\title{
Hearing New Voices: Registered Nurses and Health Technicians Experience Caring for Chronic Pain Patients in Primary Care Clinics
}

\author{
Linda H. Pellico ${ }^{*}, 1$, Wesley P. Gilliam², Allison W. Lee ${ }^{3}$ and Robert D. Kerns ${ }^{4}$ \\ ${ }^{I}$ Yale University School of Nursing, Yale University West Campus, P.O. Box 27399, West Haven, CT 06516-7399, USA \\ ${ }^{2}$ Primary Care Mental Health Integration, VA New Mexico Health Care System, 1501 San Pedro S.E. MC 116, \\ Albuquerque, NM 87108, USA \\ ${ }^{3}$ Yale School of Medicine and VA Connecticut Healthcare System, PRIME Center/11ACSLG, VA Connecticut \\ Healthcare System, 950 Campbell Avenue, Building 35A, Rm 222, West Haven, CT 06516, USA \\ ${ }^{4}$ VA Connecticut Healthcare System and Yale University, PRIME Center/11ACSLG, VA Connecticut Healthcare System, \\ 950 Campbell Avenue, Building 35A, Rm 201, West Haven, CT 06516, USA
}

\begin{abstract}
Recent national estimates from the U.S. reveal that as many as one-third of all Americans experience chronic pain resulting in high prevalence rates of visits to primary care clinics (PCC). Indeed, chronic pain appears to be an emerging global health problem. Research has largely ignored the perspective of PCC staff other than physicians in providing care for patients with chronic pain. We wanted to gain insights from the experiences of Registered Nurses (RNs) and Health Technicians (HTs) who care for this patient population. Krippendorff's method for content analysis was used to analyze comments written in an open-ended survey from fifty-seven primary care clinic staff (RNs- $\mathrm{N}=27$ and HTs-N=30) respondents. This represented an overall response rate of $75 \%$. Five themes emerged related to the experience of RNs and HTs caring for patients with chronic pain: 1) Primacy of Medications and Accompanying Clinical Quandaries; 2) System Barriers; 3) Dealing with Failure; 4) Primacy of Patient Centered Care; and 5) Importance of Team Based Care. This study demonstrates that nursing staff provide patient-centered care, recognize the importance of their role within an interdisciplinary team and can offer valuable insight about the care of patients with chronic pain. This study provides insight into strategies that can mitigate barriers to chronic pain management while sustaining those aspects that RNs and HTs view as essential for improving patient care for this vulnerable population in PCCs.
\end{abstract}

Keywords: Chronic pain, content analysis, Krippendorff method, primary care clinic.

\section{INTRODUCTION}

Chronic pain is a common problem facing healthcare personnel with prevalence rates that range from $4 \%$ to $37.5 \%$ of primary care visits in the United States (US) [1, 2]. Epidemiologic studies estimate that as many as one-third of adult Americans experience persistent pain at a cost of $\$ 635$ billion [3]. In a recent evaluation of the state of health among US citizens, low back pain, musculoskeletal disorders (presumed painful), and neck pain were identified as three of the top five diseases associated with years lived with disability in 2010 [4]. Likewise, incidence rates of chronic pain in Europe are estimated at $12-30 \%$ [5], while in Australia approximately $17 \%$ of males and $20 \%$ of females have chronic pain complaints [6]. Thus, chronic pain is emerging as a global health problem. In the US, military veterans appear to be a particularly vulnerable group with $50 \%$ of veterans reporting chronic pain [7], and prevalence

*Address correspondence to this author at the Yale University School of Nursing, Yale University West Campus, P.O. Box 27399, West Haven, CT 06516-7399, USA; Tel: 203-464-3326; Fax: 203-785-6455;

E-mail: linda.pellico@yale.edu

may be as high as $75 \%$ among female veterans of the wars in Afghanistan or Iraq [8]. In addition, reports suggest that the prevalence of pain complaints among veterans is growing steadily with each passing year $[9,10]$.

Patients with chronic pain are managed primarily in Primary Care Clinics (PCCs) and there is a dearth of literature from the perspective of PCC nursing staff. Recently, our group published qualitative data examining the experiences and viewpoints of a subset of Primary Care Providers (PCPs) who provide care to veterans with chronic pain [11]. This study extends our previous work by including Registered Nurses (RNs) and Health Technicians (HTs), to better understand their perspectives related to the management of veterans with chronic pain.

\section{BACKGROUND}

Pain is associated with elevated levels of disability, affective distress, increased healthcare utilization and engagement in risky health behaviors such as substance abuse $[7,12]$. Specialized clinics that provide interdisciplinary pain assessment and interventions have strong support for efficacy and are regarded as the "gold standard" for pain management $[13,14]$. Regrettably, such specialized services are not widely available often leaving the PCC as the 
singular setting for assessment and management of most common pain conditions.

Inherent in a collaborative care approach is the important role of RNs and HTs in primary care. Due to the complexities in managing pain, RNs and HTs are often called upon to carry out elements of pain management that exceed what PCPs can offer within the context of a standard medical appointment [15]. PCC RNs conduct routine screening for the presence and intensity of pain, conduct comprehensive pain assessments, provide patient education, promote pain self-management, and enact treatment plans, including coordination of further evaluation and access to specialty pain management services, while HTs are responsible for delegated patient care activities by the RN. All of these roles require extensive interaction with patients but also other treatment team members [16-18]. Multiple studies examining a collaborative pain management model in the PCC report improvements both in patient outcome and PCP satisfaction $[11,18,19]$. In addition, two studies note the value of HTs as health coaches in the PCC [20,21].

Continuous Quality Improvement (CQI) models of healthcare emphasize the importance of acknowledging the perspectives of all treatment team members involved in patient care as the first step in improving healthcare delivery [22]. Pain is a complex medical condition, and the knowledge generated from research on the perspectives of providers and patients solely is not enough to fully address system difficulties [23, 24]. By better understanding the perspectives of RNs and HTs, we hope to inform the efforts to improve the delivery of collaborative pain care within the PCC and across the continuum of specialty and tertiary care.

\section{MATERIALS AND METHODOLOGY}

In this descriptive study, the responses to four open ended survey questions designed to collect data about the experiences of nursing staff (RNs and HTs) in PCCs were analyzed. Open-ended questions were selected for this survey because it advances a less biased approach in comparison to forced participant responses, and facilitates spontaneity from respondents [25]. The participants responded specifically to the following questions:

1) Describe some barriers that you feel limit your ability to care for patients with chronic pain?

2) What are some of the negative aspects of caring for patients with chronic pain?

3) Describe some of the positive aspects of caring for patients with chronic pain.

4) How would you describe your role as a staff member working with chronic pain patients?

\section{Sample}

Permission to conduct the study was granted by the VA Connecticut Healthcare System (VACHS) Human Studies Subcommittee and the Yale University School of Medicine Institutional Review Board. VACHS consists of two academically affiliated VA medical centers and six community based outpatient clinics that provide healthcare to approximately 46,000 veterans. Patient Aligned Care
Teams (PACTs) at each of these settings include PCPs, RNs and HTs, and depending on several other factors, often include social workers, psychologists and/or psychiatrists, clinical pharmacists, among other staff. All RNs and HTs, at six sites within VACHS were invited to participate in this study. RNs and HTs were targeted to participate in this study because of similar and overlapping roles and responsibilities, a shared organizational link to the Nursing Service, and because HTs' roles are delegated by RNs. To facilitate recruitment, a research assistant contacted the designated point person (e.g., nurse manager) for each study site to obtain a roster of all eligible participants and scheduled a date for members of the research team to meet with potential participants at each site in a group format. Approximately three weeks prior to each scheduled group meeting, an email invitation was disseminated formally inviting participation. On the day of the meeting, participants were introduced to the study, a written study description was reviewed, and oral informed consent was obtained. Completion of the survey served as documentation of consent.

A total of seventy-five HTs and RNs from the six sites were invited to participate $(\mathrm{HTs}=45 ; \mathrm{RNs}=30)$. Of those invited, thirty HTs (67\%) and twenty-seven (90\%) RNs consented to participate in the study by completing the four item open response survey, resulting in an overall response rate of $75 \%$. Clinical managers felt it important to protect the anonymity of the respondents, particularly those from smaller clinical settings, therefore, demographic and other descriptive information that could serve to identify respondents and distinguish them from non-respondents, was not collected. Since the sample included a large proportion of the population from which it was drawn, we expect that the sample reflects the population from which it was derived. However, to provide some context of the demographics in this VHA setting, RNs and HTs are primarily female (RNs$79 \%$; HT's- 59\%), with an average age of 51.67 (SD 9.76) for RNs and 52 (SD 8.08) for HTs.

\section{Data Analysis}

Content analysis was used to identify the repetitive themes regarding participants' experience caring for a population of patients with chronic pain. This research technique "provides new insights, increases researchers' understanding of particular phenomena, or informs practical actions" [26].

Initially, a data entry assistant typed and entered into a single document all participants' written responses sorted by profession and verified as accurate by comparing them to the original survey data. Comments unrelated to the research question were excluded from analysis resulting in a sum of 4520 words. Comments ranged in length from one to 100 word responses per question, with an average length of 72 words per question.

Because we could not assume that RNs and HTs had similar experiences, each profession was initially analyzed separately. The first author read in entirety each of the professions' comments from the transcribed document so a sense of the whole could be determined and inductively coded the comments by selecting passages related to the research questions. 
A line by-line analysis of transcripts was conducted, which entailed highlighting exact words, phrases, or sentences that related to each research question, noting unique and recurrent passages. These comments were then coded or labeled with a term that denoted the description of the quote. Categories were developed with each data set (RN and HT); however because of the congruence among the two professions coded comments and emerged categories, both datasets were merged. Table 1 details the parallel responses from RNs and HTs and is offered as illustration of the rationale for merging of data sets. There were no key differences in our developed categories between the RNs and HTs. Using Krippendorff's analytical technique of clustering, the categories were clustered if they had shared characteristics, patterns, or attributes and collapsed. Dendrograms, or tree-like diagrams, were then created to illustrate how data collapsed into thematic units (see Table 2).

To assure methodological integrity, the first author created an audit trail to record reflections, evidence of consistency in coding and interpretations of data. All of the authors reviewed the audit trail and had discussions about selection of key characteristics, relationships, categories, and the development of themes until an agreement was reached.

\section{RESULTS}

Content analysis revealed five inter-related themes associated with the experience of RNs and HTs caring for veterans with chronic pain.

In response to the question, describe some barriers that you feel limit your ability to care for patients with chronic pain, two themes emerged: Primacy of Medications and Accompanying Clinical Quandaries, and System Barriers.

\section{Theme One: Primacy of Medications and Accompanying Clinical Quandaries}

A large number of comments referred to the primacy of prescription pain medications. Whether it was assessing the efficacy of pain medications, facilitating prescription refills and/or renewals, managing issues of "lost" medications, or educating patients about medications (e.g., formulary issues,

Table 1. Comparison of RNs and HTs perspective caring for patients with chronic pain.

\begin{tabular}{|c|c|}
\hline RN's Coded Comments & HT's Coded Comments \\
\hline $\begin{array}{l}\text { Role is to support patient \& provider with chronic pain management. To } \\
\text { provide education, assist pain, allow patient to express or reiterate experiences, } \\
\text { offer feedback and be advocate for patient. }\end{array}$ & $\begin{array}{l}\text { They [patients] have our teams to turn to; they get to know they have the } \\
\text { support they need. }\end{array}$ \\
\hline Futile feeling when there is not any options & $\begin{array}{l}\text { You can only do so much hearing them telling you how much pain their } \\
\text { in; you feel helpless }\end{array}$ \\
\hline Most of the patients come to PCC as walk in and time is limited. & $\begin{array}{l}\text { We are constantly made aware of Patients chronic pain by telephone, and } \\
\text { walk-in to their provider }\end{array}$ \\
\hline Constant request for increase in dose/quality of pain meds & $\begin{array}{l}\text { I see a growing trend how some patients come repeatedly as they know } \\
\text { pain = medication. }\end{array}$ \\
\hline $\begin{array}{c}\text { Feeling skeptical of whether pt. is "really in pain" or misusing (selling/giving } \\
\text { to others) }\end{array}$ & $\begin{array}{l}\text { There seems to be a real problem with drug dependence } \& \text { misuse. We } \\
\text { know there are some who genuinely need the med, but some are just } \\
\text { taking too many }\end{array}$ \\
\hline [patients] can be verbally abusive and staff does not always have recourse for this & Patients become very angry-They will call patient advocate to complain \\
\hline $\begin{array}{c}\text { After issues have been resolved, there is a sense of accomplishment. } \\
\text { Reinforcement of my belief that frequent patient contact improves their } \\
\text { outcome. }\end{array}$ & $\begin{array}{c}\text { Positive to see improvement when the patient can adjust to and live with } \\
\text { chronic pain without always having narcotics }\end{array}$ \\
\hline
\end{tabular}

Table 2. Partial dendrogram for theme: The primacy of medications and accompanying clinical quandaries.

\begin{tabular}{|c|c|c|}
\hline Participant Statements & Categories & Theme \\
\hline $\begin{array}{l}\text { Patient calling with "anger" if meds are late or delayed in } \\
\text { getting to them from the pharmacy. }\end{array}$ & $\begin{array}{l}\text { Focal point medication and negative patient } \\
\text { reaction of anger }\end{array}$ & \\
\hline $\begin{array}{l}\text { Addiction is the negative aspect when caring for patients } \\
\text { with chronic pain. }\end{array}$ & Concern of addiction & \\
\hline $\begin{array}{l}\text { Their attitude and behavior of always wanted pain } \\
\text { medication and how disruptive flow of work day. }\end{array}$ & $\begin{array}{l}\text { Focus on medication disruptive to workflow of } \\
\text { clinic }\end{array}$ & $\begin{array}{l}\text { The primacy of medications and } \\
\text { Accompanying clinical quandaries }\end{array}$ \\
\hline $\begin{array}{l}\text { Angry attitudes of patients who are unwilling to try non- } \\
\text { opiate alternatives and tapering programs }\end{array}$ & $\begin{array}{c}\text { Aberrant patient behaviors related to medication } \\
\text { tapering }\end{array}$ & \\
\hline $\begin{array}{l}\text { Some patients can be very manipulative to obtain their } \\
\text { drugs. Chronic abuse of medications and their own } \\
\text { unwillingness to accept help, inability to cope. }\end{array}$ & $\begin{array}{c}\text { Focus on medications and concerns of medication } \\
\text { abuse and patient manipulation of staff }\end{array}$ & \\
\hline
\end{tabular}


refills, opioid schedules and agreements), participants' comments revealed the pervasive influence of medications on their daily activities. RNs and HTs described their typical work day as replete with "walk-ins" or "telephone interruptions" related to veterans' "constant requests to increase dose and quantity of drug," making what was already a busy clinical day more stressful and unpredictable.

RNs and HTs comments revealed a relationship between increased patient complaints of pain to increased dosages of medications, as noted in the comments below.

"Pain levels increase so need for $\uparrow$ doses; it is a problem.” (HT)

"Constant request for increase in dose/quality of pain meds." (RN)

"The only path they [patients] see is to increase their Rx doses." (HT)

The pervasiveness of pain medications triggers clinical quandaries for RNs and HTs. Clinical predicaments revolved around the notion of balancing pain relief against actual or potential addiction, concern around abuse and diversion of opioids, and being caught in the middle between patient and provider.

As one HT noted, "Caring for patients with chronic pain can and does lead to negative outcomes such as addiction/dependence to meds that cause increases in meds that are not comfortable to many medical professional." Both RNs and HTs also suspect that some patients are "misusing" (HT) or "double-dipping and you still need to manage their requests and behaviors (RN)." One nurse described her role as one of a "traffic cop for narcotic use." Additionally, both RNs and HTs often felt caught in the middle between providers and patients, as illustrated by the following quotes.

"Being the bad guy by having to re-iterate negative responses from providers. Taking the brunt of veterans' anger when they are not happy with the outcome." (HT)

"Difficult dealing with patients who have pain and are habitual as well as they can be verbally abusive and staff does not always have recourse for this. "( $\mathrm{RN})$

Additionally, RNs and HTs express clinical difficulties navigating the goal of providing patient centered care when patient behavior is viewed as aberrant and they were "skeptical if patient is really in pain." Patient's aberrant behaviors are in conflict with the notion of providing patientcentered care. Participants described chronic pain patients as "resigned and cynical," "verbally abusive," "stressed and irritable," “manipulative," "angry," “demanding," and "uncooperative". Interestingly, each participant's description of "disruptive [patient] attitude and behavior" was universally linked with medications (wanting to increase the dose, the quantity, obtain prescription early, or change pain medication).

RNs and HTs comments suggest recognition that while they believe in patient centered care, there is a level of skepticism of both the chronic pain population and clinic staff. Skepticism was related to participants' reference to the "subjective nature of pain" and the difficulty in both "different[iating] between a drug seeker versus a patient who has uncontrolled pain" which led to feelings of uncertainty. As noted by one RN, "some providers see all vets with pain as addicts," while another RN noted "pain patients should not have to jump thru hoops to get the treatment, (opiates), that we have decided they need." A final clinical conundrum observed by a $\mathrm{RN}$ related to the standardization of obtaining urine toxicology screening, "What is the significance of the TOX screen?? We do them, but do nothing with the information. Patients get the medication regardless of TOX screen results." Refer to Table $\mathbf{2}$ for partial dendrogram.

\section{Theme Two: System Barriers}

System issues seen as barriers to chronic pain management are comprised of three categories that are structural in nature, resource driven, and include clinic design flaws. The structural barriers include the limited hours of operation of many clinics which can prevent veterans from accessing much needed clinical treatment. Compounding matters is the remote location of many clinics which places a disproportionate amount of burden on some veterans to travel long distances in order to access pain care. This is particularly problematic if a veteran lacks the financial resources necessary to make a long commute, and/or the process of "driving causes pain" for the veteran. Additionally, the size of patient examination rooms "inhibits the patient from being able to open as to the extent of his or her health."

Lack of resources for patients and providers refers to insufficient options for alternative therapies, "especially for homebound veterans", staff shortages, and lack of patient education materials. Staff shortages directly impact workers ability to care for patients. For example, HTs noted the "additional time" required to physically move patients with chronic pain into exam rooms and perform tasks such as obtaining weight. RNs also noted the "large volume of patients on provider's panels" directly limits interprofessional communication and access to "timely services" for patients. A number of RNs noted, "more staff ...would allow nurses to know well smaller group of patients." Inadequate resources also included deficient patient educational material, with particular emphasis on the need to create material to improve patients "understanding of the opioid schedule."

Clinic design flaws revolve about the inability for PCPs to access needed patient services since they "do not have permission or capability to help patients that need medications without doing a consult first." And since specialty services (pain, neurology, gerontology) have limited hours of operation, "access to timely service is a large barrier." Additionally, "off coverage hours" of PCP appears to be particularly problematic with participant comments noting times when "no provider [is] available." The need to provide written prescriptions to pharmacy also negatively impacts on provider schedule and "timely" delivery of medications. Also, RN's suggest communication efforts should be improved between providers and patients specifically related to engagement around prescription plans and opioid agreements. Finally, participants commented that the pain clinic's "lack of availability to discuss issues" and "refusing to follow some patients" is a barrier to patient 
management that requires the need for "the PCPs taking on more cases."

In response to the question about negative aspects of caring for patients with chronic pain, one theme emerged, namely Dealing with Failure.

\section{Theme Three: Dealing with Failure}

Comments depicted a sense of "futility" of RNs and HTs, and the notion that they have personally "failed" because of their inability to help relieve patients' pain. Participants described difficulty in "seeing the anguish on their faces" and noted that the "family suffer as well." They detailed frustration at seeing "failed plans", the recognition that they were "running out of options" and noted "the seemingly intractable nature of chronic pain $\&$ the failure of being able to help patients." The following two quotes support this theme.

"Futile feeling when there is not any options beside medications and traditional modes of pain relief." (RN)

"No matter what you give them for their pain they always have pain. Nothing helps." (HT)

Participant comments also described a personal failure related to a perceived inadequate knowledge base in "assessing individual pain", managing chronic pain, and insufficient understanding of pharmaceutical agents. RNs and HTs suggested additional training is necessary, with particular emphasis on developing "an organized approach to dealing with pain."

In response to the query about the positive aspects of caring for patients with chronic pain, the Importance of Team Based Care emerged.

\section{Theme four: Importance of Team Based Care}

Participant comments revealed the importance of their role within an interdisciplinary team related to improved patient outcomes, and system compliance. Collaboration between members of the team was viewed as essential in meeting patients' needs and included RNs and HTs "informing" the PCP of important clinical data, as well as "assisting" and "facilitating help to the doctor or nurse." Coordination of care was particularly important when a veteran's treatment needs exceeded the competencies of the PCC and required a referral for specialty pain services. Additionally, participants noted the importance of interprofessional support, particularly when "dealing with potentially difficult patients". The development of "standardized pain (opioid) clinic for medication renewal", "opiate agreement[s]", and "prescription guidelines" were described by respondents as important tools in improved adherence to clinical practice guidelines and evaluation of team compliance.

Participant comments suggested that "multidisciplinary teams and taking a team approach on assisting these patients with multiple issues" was beneficial for patients and PCC staff. As an RN case worker noted, "Interdisciplinary teams offer support for me to deal with vets to set boundaries and re-confirm plan." And HTs described their clinics' "positive approach - not just dispensing a narcotic- [but] teamworksupport[ive] milieu - results in positive patient interactions." Participants also described improved efficiency in their pain care processes and noted the usefulness of pain management processes such as urine toxicology screens that have decreased patients "emotional outburst in the public."

In response to the question, how would you describe your role as a staff member working with chronic pain patients?, the theme: Making a difference by providing patient centered care emerged.

\section{Theme Five: Making a Difference by Providing Patient Centered Care}

RNs and HTs describe their role relative to their professional function and responsibilities; RNs comments concern patient assessment, coordination of patient care, monitoring of treatment outcomes, referrals, and patient education, while HTs comments related to a variety of delegated procedural tasks such as obtaining vital signs, weights, and pain intensity ratings, electrocardiograms, and urine toxicology specimens. However, participant comments clustered around the primacy of humanistic patient centered care. They detailed treatment approaches that include "listening," "educating," "sympathizing," "giving hope," "accommodating to patient behaviors," and "engaging veterans," as not only helpful to patients, but also as a source of professional satisfaction.

Participant comments revealed awareness that their knowledge and personal actions have positive consequences for patients. As a result of their provision of compassionate care "people really can improve their function." Improved quality of life for patients in the form of "improved sleep, lengthening the duration of pain relief," "improved coping," "improved patient self-care management," "improved [activities of daily living] ADLs," and "getting some vets to recognize substance abuse issues and getting them into treatment," are directly correlated to their personal humanistic approaches. While both HTs and RNs note the importance of providing patients with chronic pain with compassionate care, the RNs note that their role is to work with other members of the team to "help [providers] understand that patients with chronic pain should be treated with care \& dignity."

\section{DISCUSSION}

To our knowledge, this is the first study to utilize a qualitative methodological approach to capture the experience of PCC RNs and HTs involved in the treatment of veterans' with chronic pain conditions. RNs and HTs point out both provider and system level deficits that must be addressed in order to appropriately care for this vulnerable population. Such insight could be used to inform continuous quality improvement (CQI) efforts designed to increase adherence to evidence-based practices for treatment of pain in PCCs. Themes that characterized perceived positive aspects of working with veterans' with chronic pain were also identified and could incentivize commitment to CQI efforts. Importantly, the results of our study document the shared experiences of RNs and HTs in caring for veterans 
with chronic pain and encourage consideration of both groups as members of veterans' care team.

Multiple barriers to the provision of effective pain management were identified by study participants. System factors related to inadequate knowledge of pain management and approaches to communicating with patients with complex pain conditions, especially in the area of opioid management, were paramount. Also highlighted were organizational barriers that compromised the primary care teams' ability to enact comprehensive pain management approaches established by the patients and his/her team members. Another perceived barrier isolated by our analyses relates to the interpersonal challenges associated with delivering pain care; specifically, difficult staff - patient interactions. Many of the barriers identified by this study parallels data from our earlier researchof PCP's in the same healthcare network [11]. Our findings suggest that, similar to primary providers, PCC RNs need training and support in areas of pain assessment, pharmacology, specifically opioid management, and the role on non-pharmacologic interventions to address these practice deficits.

Efforts targeting the knowledge and competency gaps identified by RNs in our study should begin in nursing school. In a recent study of 96 nursing school faculty, less than half $(36.5 \%)$ of faculty felt adequately prepared in their overall knowledge of pain, yet $62.5 \%$ of these faculty were responsible for teaching the next generation of nurses [27]. Of particular concern is the finding that less than half of the faculty used specific pain management guidelines in their instruction, and areas of faculty weakness were found in medications, interventions, and addiction, which were perceived as vulnerabilities in our respondents. This finding is disconcerting and illustrates a need to re-evaluate and restructure the nursing curriculum to include chronic pain management in order to ensure that future nurses are prepared to assist in the care of this highly prevalent disease. In the clinical setting, practicing nurses would benefit from exposure to continuing education opportunities that promote uptake of latest knowledge and standards of pain management. A key initiative is the Pain Resource Nurse (PRN) program that has developed a curriculum of continuing education for nurses and for promoting their roles as champions/resources in inpatients and outpatient settings $[28,29]$. Such efforts could be supplemented by increasing the publicity of current pain resources available on-line for students, faculty, and practicing RN's (refer to Table $\mathbf{3}$ for list of web-based pain resources).

With respect to HTs, a recent study by Adair et al. [30] revealed that non clinical lay persons trained for two weeks in a PCC improved management outcomes for assigned patients with diabetes, hypertension, and congestive heart failure. These findings suggest that non-licensed HTscan also play a role in facilitating important health behavior change within the PCC contexts and efforts directed towards providing additional education for HTs in chronic pain management could be profitable.

Many of the system barriers could be improved through more effective use of collaborative, team-based approaches to primary care that are consistent with a Patient Centered Medical Home model [31]. The PCC team including RNs and HTs need to work together to address administrative issues such as opioid agreements, urine toxicology screens, and telephone communication, as well as caring for patients who unexpectedly "walk-in" to clinics with concerns about their pain treatments. Improvement in patient satisfaction and pain intensity ratings were seen when nurse care coordinators provided support to patients with chronic noncancer pain $[18,23]$. Opioid renewal clinics can expand PCC capacity to manage chronic pain by assigning dedicated staff to manage opioid prescriptions and monitor high risk patients that account for a disproportionate number of medication related "walk-ins" and "telephone interruptions" that interfere with efficient PCC work flow and contribute significantly to RN, HT and PCP stress $[11,19]$.

The theme of challenging and antagonistic patient encounters was a pervasive one in this study. RNs and HT frequently cited examples of feeling "caught in the middle" when PCP and patients have differing expectations with respect to pain care. Lack of concordance between the PCP and patient can leave RNs and HTs with the unenviable task of attempting to restore the physician-patient relationship following a potentially acrimonious clinical encounter which can then lead to strained, even hostile interactions between staff members and patients. Many RNs and HTs internalized their lack of success with veterans suffering with chronic pain as failure resulting in frustration and disappointment. Suggested solutions include goal setting with patients who often have unrealistic expectations of " $100 \%$ pain relief" [32, 33, p. 107], conflict resolution training for all team members, and education in interdisciplinary teamwork and communication [34].

The positive factors identified in this study that facilitate optimal pain care from the perspective of participants are equally interesting and address a real paucity in the literature. While RNs and HTs viewed themselves as responsible for basic care needs (e.g., obtaining vital signs and pain intensity ratings), they also perceived their role as one of providing patient-centered care characterized by empathic approaches to communicating with and treating patients in pain. This finding is noteworthy considering that empathy is a core element of patient-centered care and recognized as essential when managing patients with chronic pain $[35,36]$. Indeed, recent empirical inquiry supports the salutary effects an empathic nursing staff can have on outcomes among patients receiving care within PCC for chronic pain [23, 24, 37].

Also noteworthy was RNs and HTs recognition of the importance of the role of interdisciplinary team care on patient outcomes and system compliance with clinical practice guidelines. Participants described a well-functioning interdisciplinary team as one that includes RNs, HTs and providers working in a collaborative environment with ongoing open communication as well as appropriate consensus building and conflict resolution. It was also acknowledged by a number of RNs that effective interdisciplinary communication provides a level of emotional support often needed when attempting to manage complex chronic pain cases that can involve issues of opioid misuse or abuse. RNs feel empowered to take a more active role in working with patients with pain when they know that have the support of their colleagues [19]. 
Table 3. Web Based Resources for Nurses

\begin{tabular}{|c|c|}
\hline $\begin{array}{l}\text { Agency for Healthcare Research and Quality (AHRQ) Evidence-based Practice Guidelines; Specific guidelines } \\
\text { include Cancer pain management and chronic non cancer pain. AHRQ provides several free continuing education } \\
\text { events in the areas of comparative effectiveness, quality and patient safety, and prevention/care management }\end{array}$ & Free \\
\hline $\begin{array}{l}\text { City of Hope Palliative Care Resource Web Site* This web page contains a collection of links to a broad range of } \\
\text { resources for the assessment and treatment of pain. Although the primary focus of the site is palliative care, } \\
\text { it provides a significant number of links to general pain management resources. }\end{array}$ & $\begin{array}{l}\text { Pain Resource Nurse (PRN) training } \\
\text { program is associated with fee }\end{array}$ \\
\hline $\begin{array}{l}\text { Nurse.com features a variety of educational programs including pain management. } \\
\text { http://ce.nurse.com/pain-management }\end{array}$ & $\begin{array}{l}\text { Contact hours awarded, some } \\
\text { educational activities are free, fee } \\
\text { for CEU's variable for specific } \\
\text { courses. }\end{array}$ \\
\hline $\begin{array}{l}\text { Geriatric Pain website; http://www.geriatricpain.org/Content/Education/Provider/Pages/default.aspx; this site also } \\
\text { includes Geriatric ELNEC (End of Life Nursing Education Consortium) - a national end-of-life educational } \\
\text { program administered by the City of Hope National Medical Center (COH) and the American Association of } \\
\text { Colleges of Nursing (AACN) }\end{array}$ & $\begin{array}{l}\text { The web site is made possible by } \\
\text { generous funding from The Mayday } \\
\text { Fund }\end{array}$ \\
\hline $\begin{array}{l}\text { American Academy of Pain Management online education center; Two free programs with CEU: Improving the } \\
\text { Quality of Care for Patients with Rheumatoid Arthritis and Mind, Body, Spirit Solutions: An Integrative Approach } \\
\text { to Fibromyalgia; however many additional programs available for fee }\end{array}$ & $\begin{array}{l}\text { This site offers a host of Continuing } \\
\text { Education opportunities. Cost for } \\
\text { Nurses to become members in } \\
\text { Academy is } \$ 225\end{array}$ \\
\hline $\begin{array}{l}\text { The American Society for Pain Management Nursing is an organization of professional nurses dedicated to } \\
\text { promoting and providing optimal care of individuals with pain, including the management of its sequelae. This is } \\
\text { accomplished through education, standards, advocacy, and research. There are a variety of position papers } \\
\text { downloaded for free }\end{array}$ & $\begin{array}{l}\text { This site offers educational } \\
\text { programs, Cost for active members } \\
\text { is } \$ 125\end{array}$ \\
\hline $\begin{array}{l}\text { American Chronic Pain Association; This organization facilitates peer support and education for individuals with } \\
\text { chronic pain and their families so that these individuals may live more fully in spite of their pain; } \\
\text { http://theacpa.org/Pain-Management-Programs }\end{array}$ & $\begin{array}{l}\text { Free site for patients and families of } \\
\text { those with chronic pain }\end{array}$ \\
\hline American Pain Society; offers a variety of clinical practice guidelines for free & $\begin{array}{l}\text { Variable cost for membership } \\
\text { depending on annual income }\end{array}$ \\
\hline $\begin{array}{l}\text { The International Association for the Study of Pain (IASP) is the leading professional forum for science, practice, } \\
\text { and education in the field of pain. Membership in IASP is open to all professionals involved in research, diagnosis } \\
\text { or treatment of pain; http://www.iasp-pain.org/AM/Template.cfm?Section=Nursing }\end{array}$ & $\begin{array}{l}\text { Variable cost depending on annual } \\
\text { income }\end{array}$ \\
\hline $\begin{array}{l}\text { National Hospice and Palliative Care Organization; a variety of eweb based educational programs are available; } \\
\text { http://www.nhpco.org/education/online-learning }\end{array}$ & $\begin{array}{l}\text { Fee for membership, variable cost } \\
\text { for educational programs depending } \\
\text { on membership }\end{array}$ \\
\hline $\begin{array}{l}\text { National Center for Complementary and Alternative Medicine, National Institutes of Health; NCCAM is offering } \\
\text { free, comprehensive video-lectures about research in complementary health approaches. Topics range from mind- } \\
\text { body pain therapies to acupuncture; http://nccam.nih.gov/ }\end{array}$ & $\begin{array}{l}\text { Free video-lectures; clinical practice } \\
\text { guidelines, for health professionals, } \\
\text { also offers information for patients } \\
\text { available free }\end{array}$ \\
\hline $\begin{array}{l}\text { National Comprehensive Cancer Network Guidelines; offers adult cancer pain guidelines; } \\
\text { http://www.nccn.org/professionals/physician_gls/f_guidelines.asp\#pain }\end{array}$ & Requires registration on line, no fee \\
\hline $\begin{array}{l}\text { Unites States Department of Veterans Affairs; VHA pain management site: This website facilitates effective pain } \\
\text { management by providing convenient, centralized access to resources for the provision of pain services within the } \\
\text { VA healthcare system. The intended users of this site are veterans, veterans' family members, caregivers, VA } \\
\text { administrators, clinicians, and researchers who have an interest in any aspect of pain management; } \\
\text { http://www.va.gov/PAINMANAGEMENT/Clinical_Resources.asp }\end{array}$ & $\begin{array}{l}\text { Free educational resources including } \\
\text { clinical tools, clinical practice } \\
\text { guidelines }\end{array}$ \\
\hline
\end{tabular}

This study has several limitations. Our sample size is limited in that we surveyed 57 staff members from a single state-wide Veterans Health Administration (VHA) system. Although we sampled staff members of different clinics from both urban and rural, and academically affiliated and nonaffiliated settings to maximize the variation in staff experience with patients with chronic pain, it is still possible that clinical or social characteristics unique to the veteran population could have impacted our outcomes. Additionally, the limited word count in this open ended survey and the lack of interaction that would have been provided from faceto-face interviews should be considered. It is also important to note that these results may not generalize to other staff members in settings outside of the VHA, given veterans' unique military experiences and the high prevalence of comorbid medical and psychiatric disorders among veterans.
However, this seems unlikely considering the literature suggests that the experiences expressed by participants in this study were not unusual $[38,39]$.

\section{CONCLUSION}

Results of this study draw attention to the important voices of RNs and HTs in promoting optimal care for persons with chronic pain. They offer care at the forefront of persons' interface with the healthcare system and are particularly well positioned to identify gaps and strengths of the healthcare system as it works to improve pain care. RNs specialized skills in leadership, communication, patient/ family advocacy, patient education, and empathy are particularly well suited for patient-centered approaches to pain. However, the potential clinical impact of these unique skill 
sets is often mitigated by a lack of education and understanding of pain assessment and management. As RNs likely spend more time with patients in pain than any other member of the PCC team, targeted approaches to enhancing the pain management competencies of nurses in this setting is critical to assure that primary care staff can continue to place patients at the center of care. Chronic pain management needs to be prioritized in nursing school curricula and continuing education initiatives mandated in order to prepare our current nurses and nurses of the future to meet the clinical needs of this complex and burgeoning patient population. Similar deficiencies in the training of HTs should also be addressed.

Interestingly, the themes that emerged largely echo the recommendations from the recent Institute of Medicine (IOM) report calling for a transformation of pain care in American [3]. Their emphasis on patient-centered and multidisciplinary care as foundational for pain care CQI efforts is particularly noteworthy. Their acknowledgement of gaps in knowledge and competencies and their interest in obtaining education and training to address them is similarly highlighted in the IOM report and its recommendations for improving professional education. Participants questions about the benefits and safety of opioid therapy, particularly in the context of the complexity of chronic pain and medical and mental health co-morbidities, is entirely consistent with national initiatives to address these challenges such as the National Prescription Drug Abuse Prevention Strategy [40]. Finally, the themes that emerged from this study are consistent with VHA's Stepped Care Model of Pain Management that highlights the need to assess and manage most common pain conditions in the primary care setting through high performing Patient Aligned Care Teams including RNs and HTs [14].

Chronic pain is a pervasive problem RNs and HTs encounter in all clinical settings. Despite national painrelevant CQI initiatives, results of this study reveal that RNs'and HTs' knowledge of pain management is a perceived weakness mandating a need for educational interventions. Pain management that includes evidencebased research and current standards of care should be required content in nursing school curricula. Similar refinement of HT training curricula should be considered. In addition, RNs and HTs should be encouraged to improve their knowledge level via the numerous web-based continuing education resources. Finally, RNs and HTs perceived their role as one of providing patient-centered care characterized by empathic approaches to communicating with and treating patients with chronic pain and confirms the importance of interdisciplinary teams in managing chronic pain.

\section{ABOUT THE AUTHORS}

Dr. Pellico is an Associate Professor at Yale University School of Nursing and is a qualitative researcher with over 35 years of clinical experience. She has researched and published in the field of nursing education, newly licensed Registered Nurses experience, chronic pain management and creative teaching pedagogy.
Dr. Gilliam is a pain psychologist housed in Integrated Primary Care at the New Mexico VA Healthcare System, and a researcher with numerous peer-reviewed publications examining psychosocial variables related to both acute and chronic pain.

Allison Lee has been a Research Assistant with the Yale School of Medicine for 7 years and the PRIME center for 3 years with a research focus on chronic pain in the Primary Care setting.

Robert Kerns is National Director of Pain Research for the Veterans Health Administration (VHA), Director of the VHA's Pain Research. Informatics, Multimorbidities and Education (PRIME) Center, and Professor of Psychiatry, Neurology and Psychology at Yale University. He is a clinical psychologist with over 35 years of experience as a clinician, educator, scientist, administrator, and policy advisor and advocate in the area of pain and pain management.

\section{DISCLAIMER}

The views expressed in this article are those of the authors and do not necessarily reflect the position or policy of the Department of Veterans Affairs or the United States government.

\section{CONFLICT OF INTEREST}

The authors confirm that this article content has no conflict of interest.

\section{ACKNOWLEDGEMENTS}

This research study was supported in part by the Department of Veterans Affairs, Veterans Health Administration, Office of Research and Development, Health Services Research and Development Service Research Enhancement Award Program (REAP 08-266); a Program for Research Leadership Award from The Patrick and Catherine Weldon Donaghue Medical Research Foundation and Mayday Fund.

The researchers wish to acknowledge our colleague Patricia H. Rosenberger, PhD, Psychologist at the VA Connecticut Healthcare System and Assistant Professor at the Yale University School of Medicine who assisted in development of our overall research plan, and study oversight, but passed away suddenly before completion of this study.

\section{REFERENCES} O'Connor PG. Use of opioid medications for chronic noncancer pain syndromes in primary care. J Gen Int Med 2002; 17: 173-9.

Upshur CC, Luckman RS, Savageau JA. Primary care provider concerns about management of chronic pain in community clinic population. J Gen Int Med 2002; 21: 652-5.

[3] Institute of Medicine of the National Academies. Relieving pain in America: A blueprint for transforming prevention, care, education, and research. Washington DC: The National Academies Press 2011.

[4] US Burden of Disease Collaborators (2013). State of US health: 1990-2010: Burden of diseases, injuries, and risk factors. J Am Medical Assoc 2013; 310 (6): 591-608. 
[5] Breivik H, Collett B, Ventafridda V, Cohen R, Gallacher D. Survey of chronic pain in Europe: prevalence, impact on daily life, and treatment. Eur J Pain 2006; 10(4): 287-333.

[6] West C, Usher K, Foster K, Stewart L. Chronic pain and the family: The experience of the partners of people living with chronic pain. J Clin Nurs 2012; 21(23-24): 3352-60

[7] Kerns RD, Otis J, Rosenberg R, Reid MC. Veterans' reports of pain and associations with ratings of health, health-risk behaviors, affective distress, and use of the healthcare system. J Rehab Res Develop 2003; 40, 371-9.

[8] Clark M E. Post-deployment pain: A need for rapid detection and intervention. Pain Med 2004; 5, 333-4.

[9] Haskell SG, Heapy A, Reid MC, Papas RK, Kerns RD. The prevalence and age-related characteristics of pain in a sample of women veterans receiving primary care. J Women's Health 2006; 52: 862-9.

[10] Bosco M, Murphy J, Clark M. Chronic pain and traumatic brain injury in OEF/OIF service members and veterans. Headache 2013; 53(9): 1518-22

[11] Lincoln LE, Pellico L, Kerns R, Anderson D. Barriers and facilitators to chronic non-cancer pain management in primary care: A qualitative analysis of primary care providers' experiences and attitudes. Palliative Care and Medicine 2013; S3: 001. doi:10.4172/2165-7386. S3-001

[12] Compton P, Athanasos P. Chronic pain, substance abuse, and addiction. Nurs Clin North Am 2003; 38, 525-37.

[13] Flor H, Fydrich T, Turk DC. Efficacy of multidisciplinary pain treatment centers: A meta-analytic review. Pain 1992; 49: 221-30.

[14] Scascighini L, Toma V, Dober-Spielmann S, Sprott H. Multidisciplinary treatment for chronic pain: A systematic review of interventions and outcomes. Rheumatology 2008; 47: 670-8.

[15] Richardson C, Poole H. Chronic pain and coping: A proposed role for nurses and nursing models. J Adv Nurs 2001; 34: 659-67.

[16] Compton P. The role of urine toxicology in chronic opioid analgesic therapy. Pain Manag Nurs 2007; 8: $166-72$.

[17] Lamb L, Pereira JX, Shir Y. Nurse case management program of chronic pain patients treated with methadone. Pain Manag Nurs 2007; 8: 130-8.

[18] Matthias MS, Bair MJ, Nyland KA, et al. Self-management support and communication from nurse care managers compared with primary care physicians: A focus group study of patients with chronic musculoskeletal pain. Pain Manag Nurs 2010; 11: 26-34.

[19] Wiedemer NL, Harden PS, Arndt IO, Gallagher RM. The opioid renewal clinic: A primary care, managed approach to opioid therapy in chronic pain patients at risk for substance abuse. Pain Med 2007; 8: 573-84.

[20] Chen EH, Thorn DH, Hessler DM, et al. Using the teamlet model to improve chronic care in an academic primary care practice. J Gen Int Med 2010; 25 (Suppl. 4); 610-4.

[21] Gensichen J, von Korff M, Peitz M, et al. Case management for depression by health care assistants in small primary care practices: A cluster randomized trial. Ann Int Med 2009; 151: 369-78.

[22] Kritchevsky SB, Simmons BP. Continuous quality improvement: Concepts and applications for physician care. J Am Med Assoc 1991; 266: 1817-23.

[23] Bair M, Matthias MS, Nyland KA, et al. Barriers and facilitators to chronic pain self-management: A qualitative study of primary care patients with comorbid musculoskeletal pain and depression. Pain Med 2009; 10: 1280-90.

[24] Matthias MS, Parpart AL, Nyland KA, et al. The patient-provider relationship in chronic pain care: Providers' perspectives. Pain Med 2010; 11: 1688-97.

[25] Niedomysl T, Malmberg B. Do open-ended survey questions on migration motives create coder variability problems? Population, space, place 2009; 15: 79-86.

[26] Krippendorff K. Content Analysis: An Introduction to its Methodology, $3^{\text {rd }}$ ed. Sage Publications, Inc., Thousand Oaks 2013; California

[27] Voshall B, Dunn K, Shelestak D. Knowledge and attitudes of pain management among nursing faculty. Pain Manag Nurs 2012; Retrieved from doi: 10.1016/j.pmn.2012.02.001

[28] Ferrell BR, Grant M, Ritchey KJ, Ropchan R, Rivera LM. The pain resource nurse training program: A unique approach to pain management. J Pain Symp Manag 1993; 8: 549-56.

[29] Ladak SSJ, McPhee C, Muscat M, et al. The journey of the pain resource nurse in improving pain management practices: Understanding role implementation. Pain Managt Nurs 2013; 14: 68-73.

[30] Adair R, Christianson J, Wholey DR, et al. Care guides: employing nonclinical laypersons to help primary care teams manage chronic disease. J Amb Care Manag 2012; 35(1): 27-37

[31] Rittenhouse DR, Shortell SM. The patient-centered medical home: Will it stand the test of health reform. J Am Med Asso 2009, 301, 2038-2040.

[32] Filoramo MA. Improving goal setting and goal attainment in patients with chronic noncancer pain. Pain Manag Nurs 2007; 8: 96-101.

[33] Manchikanti L, Singh V, Caraway DL. Benyamin. Breakthrough pain in chronic non-cancer pain: Fact, fiction, or abuse. Pain Physician 2011; 14: E103-117.

[34] Pellico L, Djukic M, Kovner C, Brewer C. Moving on, up, or out changing work needs of new RNs at different stages of their beginning nursing practice. Online J Issues Nurs 2009; 1: Retrieved from:

www.nursingworld.org/MainMenuCategories/ANAMarketplace/A NAPeriodicals/OJIN/TableofContents/Vol152010/No1Jan2010/Art icles-Previous-Topic/Changing-Work-Needs-of-New-RNs.aspx

[35] Banja JD. Empathy in the physician's pain practice: Benefits, barriers, and recommendations. Pain Med 2006; 9: 1125-9.

[36] Gallagher RM. Empathy: A timeless skill for the pain medicine toolbox. Pain Med 2006; 7: 213-14.

[37] Smeeding SJW, Bradshaw DH, Kumpfer KL, Trevithick S, Stoddard GJ. Outcome evaluation of the veterans affairs Salt Lake City integrative health clinic for chronic nonmalignant pain. Clin J Pain 2011; 27: 146-55.

[38] Adams NJ, Plane MB, Fleming MF, Mundt MP, Saunders LA, Stauffacher EA. Opioids and the treatment of chronic pain in a primary care sample. J Pain Symp Manag 2001; 22: 791-6.

[39] Buse DC, Lipton RB. Facilitating communication with patients for improved migraine outcomes. Current Pain Headache Rep 2008; 12: $230-6$.

[40] Office of National Drug Control Policy (2010). National Prescription Drug Abuse Prevention Strategy. Washington, DC: The White House. 